\title{
Why Weary Metal Fails Under Light Loads
}

\section{The Causes of Steel Fatigue, and the Ticklish Problem of Testíng Against It}

\author{
By George H. Dacy
} \begin{abstract}
MOTOR truck accustom-
ed to handling loads of six to ten tons may collapse due to axle failure when the only burden the machine is carrying is the driver. A street car which handles 100 passengers during the peak traffic hours of the day may wreck due to axle or wheel collapse when it is returning to the car barn to be greased. An elevator which is adapted to carry 20 persons may crash to its basement pit when empty. Even bridge girders which have been designed to support enormous stress and strain may break down under light loads. Not infrequently serious automobile, street-car, elevator and bridge accidents occur which result in heavy losses in limb and life just because some of the metal parts used in
\end{abstract} the construction of the ve-

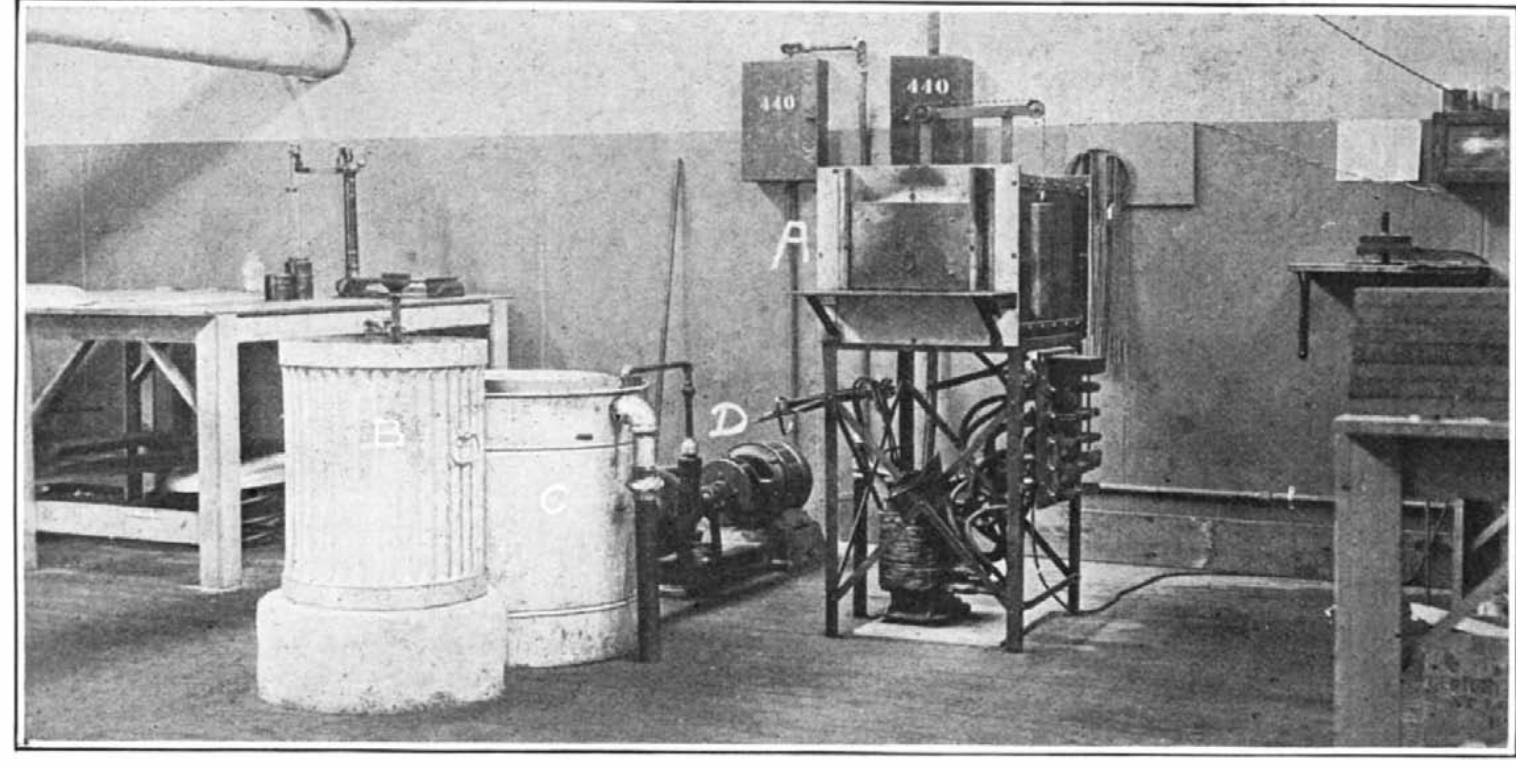

$A-$ Electrically-heated furnace. $B$-Water-quenching tank. $C$-Oil-quenching tank. $D$-Oil-circulating pump

Laboratory apparatus for reproducing the conditions of heat treatment

these tests merits a distinguished service cross denoting special strength superiority. These middle western . engineers have devised tests which expose the metal samples to every conceivable stress and strain under regular repetitions.

Metals while being subjected to fatigue in these experiments have been observed under the microscope and it has been found that the crystals of which a metal is composed will allow deformation to occur by movement along certain gliding planes within the crystal. This gliding or slipping is indicated by the appearance of lines running across the crystals. They are called "slip bands" and careful examination has elicited the facts that the slipping cause microscopic ridges and de hicles 0

larly, the steering knuckle or crankshaft, springs, axles or engine parts of the motor car apparently may look fit and strong yet under service when the driver least anticipates a breakdown, one of these parts may disrupt. That is why the need is urgent for some method of standardized testing which will admit the prediction of the actual use and strain which the different metal materials will survive. Vital statistics are needed which will forecast the lifetime of steel and iron so that approaching failures may be noticed and guarded against.

Studies of why metals under light loads, frequently repeated, failed more rapidly than they did under heavier burdens of a more uniform pressure have been in progress for the last 60 years. German scientists conducted many tests and devised methods which are incomplete when measured in terms of modern machinery, mainly because they are of such short duration and because since those tests many new kinds of steel have come into use and new metals such as aluminum are available for building machines. The inadequacy of these investigations led to the conception of the series of strength tests devised by Professor $\mathrm{H}$. $\mathrm{F}$. Moore and his talented assistants. Any metal that survives intricacies which, previously have obscured the engineer's knowledge concerning the everyday history of steel and metal materials and their reactions to continuous serv-

A modern Goliath of professional weight-lifters for many years may excel all his rivals in remarkable feats of strength. Then due to excessive use of certain muscles or on account of old age, he may begin to slow up; his muscles are unable to respond so adeptly to the dictates of his will. $\mathrm{He}$ has to reduce the weight of his dumb bells, bar bells and cannon balls. Gradually, he fails in health and strength and ultimately, he is obliged to abandon his exhibition work. Now unlike the h u m a n metabolism, the strength of metals gives was all of a sudden without any indication of impending failure The line shaft in a machine shop may have been in active service only a few years and appear as good as new - yet, unexpectedly, it may fail and cause a costly and serious accident. Simi-

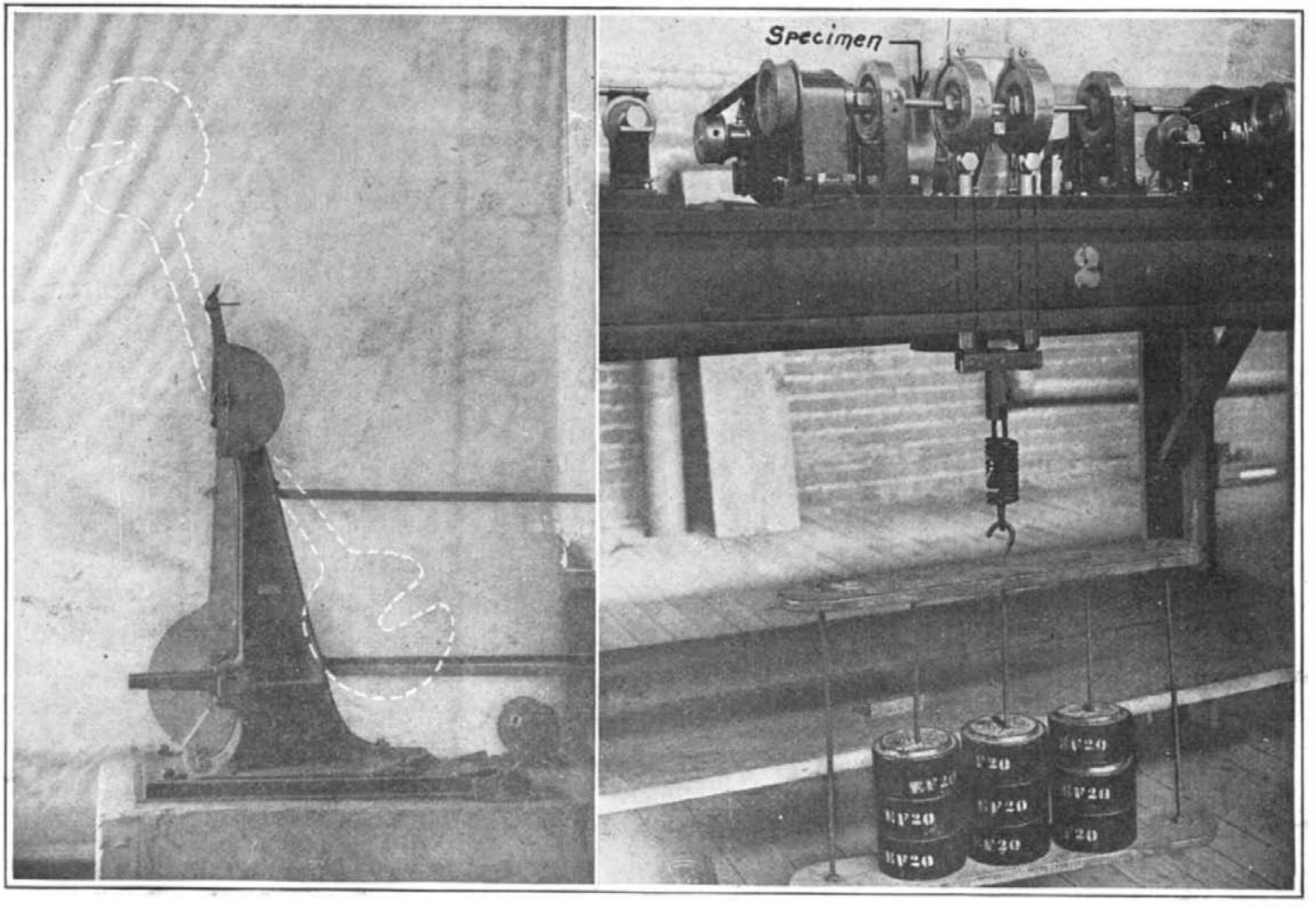

Left: Single-blow impact-testing machine. Right: Rotating-beam testing machin Some of the apparatus that induces weary steel to tell its story pressions of the surface, in the nature of steps. As the test of the material fatigue is continued, the slip bands become more numerous, and also broaden. Final, some of the bands deve and thus causes failure. Therefore, it appears that the primary cause of fatigue failure is localized deformation. Because steel is composed of many minute crystals-in ordinary steel there are at least two different kinds-the structure is not ikely to be homogeneous. Furthermore, there are likely to occur many microscopic flaws throughout the material. Hence somewhere in the sample, there will be high local stresses due either to non-homogeneity or to flaws, and at such points, the sample will be liable to deteriorate by the repeated action of fatigue stresses. The presence of internal stresses, due to previous heat treatinent or mechanical treatment, would also tend to weaken the material when fatigue stresses of a similar character are applied later.

The Illinois experiments feature the repeated stress of steel under regular repetition and are accompanied by very careful static tests, impact tests, and special magnetic tests. An endurance limit of $100,000,000$ cycles or repetitions was decided upon and it has been determined that ever sample which survives this strength is adequate for the most rigorous field service. To illustrate the severe wear to which the metal parts are exposed in actual service-it is worthy of note that in the case of a steam turbine rotating at a speed of 3,000 revolutions a minute, the shaft suffers a reversal of bending stress every revolution. The average life of a steel turbine blade is $\mathbf{1 0}$ years during which it is exposed to something like $15,000,000,000$ such bending strains. Under such service, any flaw or defect is sure:to show. As a result of these new experiments, henceforward, it will be possible to locate these defects in the testing laboratory before the turbine blade is made. The ap̉proxînate number of repetitions of stress in the normal lifetime of the following structural and machine parts are railroad bridge chord members, $2,000,000$ : eleyated railroad structure, floor beams, $40,000,000$; railroad rail, locomotive wheel loads, 500,000 - railroad rail, car wheel loads, 15,000,000; air. 
plane engine crankshaft, $18,000,000$; car axles, 50,000,000; automobile engine crankshaft, 120,000,000; line-shafting in shops, $360,000,000$ and steam engine piston rods, connecting rods and crankshafts, $1,000,000$ 000.

Professor Moore has been working to perfect a commercial method for predicting the fatigue of different steels and irons and in this research work he is testing out all the related laboratory methods and laws. From each sample of steel, he machines 20 specimens each of which is 4 inch in diameter and 13 inches long. Some of the samples are first submitted to physical tests which subject the steel to stretch and deformation tests and under stretching pressure of 10,000 or 12,000 pounds or whatever amount is required stretch the steel sample out like taffy candy until it "necks down" and finally breaks. The heaviest, steady load test machine in use in the Illinois University laboratories has a capacity of 600,000 pounds. A special, electrically driven machine with a backward and forward vib-
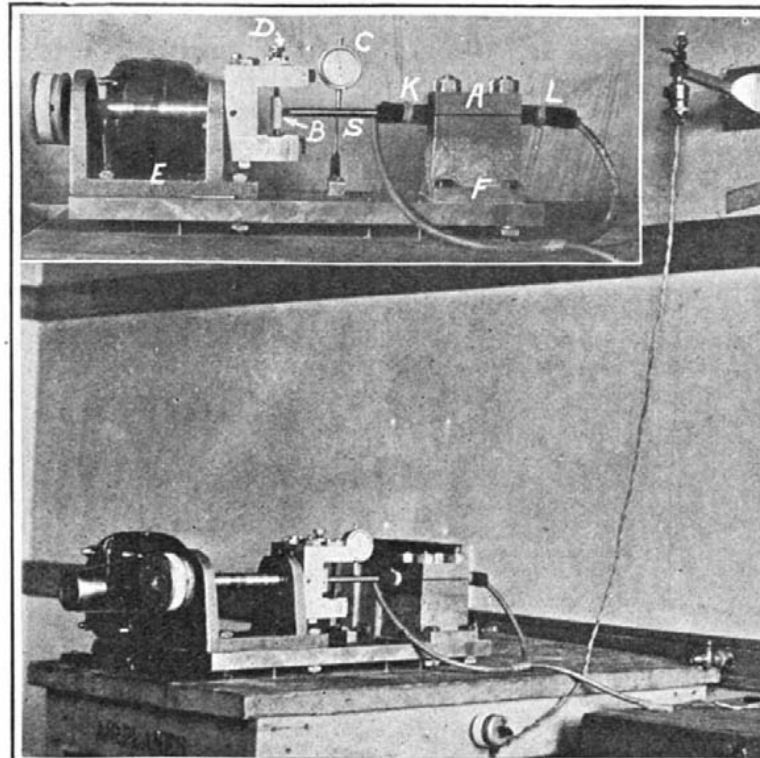

Machine that ration is so equipped with heavy springs that the amount of compression is recorded by a special attachment in graph form indicative of the repetition strength of the sample under vibratory strain.

A battery of 15 stress machines of the rotating beam type-really facsimiles of a freight car axle upside down-are so arranged that every rotation of each machine reverses the stress on the sample which is being tested on it. The steel sample is inserted like an axle in this machine and is rotated at the rate of more than 2,000,000 revolutions a day. These test conditions duplicate closely those of the ordinary railroad car or automobile axle in motion. Each test is continued for 45 days when the samples will have been exposed to $100,000,000$ repetitions of stress. Samples that withstand this modern, mechanical, torture chamber successfully are qualified as "endurance satisfactory" for the purpose intended. The arrangement is such that if the sample collapses before the completion of the test, an electrical connection is broken automatically and the machine stops. A special counter is used on each machine to record the number of revolutions. The experiments have demonstrated the general fact that if the steel samples do not fail by the time they make $10,000,000$ revolutions, they will survive the strength test of $100,000,000$ rotations on the machine; and so far as can be predicted from the test results, will survive an indefinite number of repetitions of stress.

"The action upon the steel in the testing machines is in the nature of a constant backward and forward bending motion," reports Professor Moore. "For example, a wire will bend double once without breaking but if you wiggle it back and forth a few times, it invariably will snap. When a car axle stands a rest, the upper portion suffers tension from the weight sustained at each end. Simultaneously, the lower surface is being exposed to compression or crushing action. If the axle is rotated a half turn, this condition of the wheel sections is reversed. In a word, the whee is undergoing the same action as that which snapped off the wire -a much severer test than to support a single, stationary load. The microscope shows that a peculiar action occurs in the internal structure of the steel during this process. After repeating stress, stee will snap almost without any warning; while under single heavy load, it will crumple. In the forme instance, the steel behaves as though it were a brittle instead of a ductile metal,"

A peculiar pendulum-like hatchet is the outstanding feature of another testing machine which is used to subject the steel samples to abrupt and rapid shock and jar. A small notch is cut in the steel rod which then is placed in position so that it will receive the full impact of the pendulum as it completes its swin through an arc of 160 degrees. Special records are kept of the breaking strength of the steel rods in this test. Another repeated impact machine is so adjusted and mounted that it hammers the test samples first on one side and then on the other. Another sensitive machine is equipped with a microscopic arrangement so that it registers very slight deflections of the steel
However, these under delicate pressure. How under heavy, sudden impact do not seem to give any reliable index of the seem to give any reliable index of the
ability of the steel to withstand million. of repetitions of light loads. One of the purposes of the extensive investigations under the direction of Professor Moore has been to devise a short cut, abridged system of testing steel samples which is efficiently adapted for general utilization in commerce and industry.

The principles of this new test were suggested several years ago by an English engineer named Stromeyer but the in fallible reliability of the test and methods for its most efficient performance have been worked out at the University of Illinois. 'The machine for making the new test is inexpensive. It can be applied, in some cases, to machine parts which are to be used in actual service, as the test doe not injure the specimen tested. It may be possible to test an automobile crankshaft, an elevator wire rope, a bridge girder, a car axle or a railroad rail before these respective parts are installed.

It has been found that if under repeated loading incipient cracks begin to form, then the formation of these cracks is accompanied by a very slight rise in temperature - a small fraction of a degree. This rise of temperature occurs in a minute or two after the repetitions of stress have begun. The proposed test for "fatigue" developed at Illinois University is in effect the application of a clinical thermometer to a steel specimen to which repeated stress is applied.

A vise is used which holds one end of a specimen, and an adjustable eccentric which "wobbles" the other end of the specimen by any desired amount. A micrometer is used to measure the amount of "wobble" which determines the amount of stress applied. The "clinical thermometer" used is really a delicate electric thermo-couple which is held against the specimen at the point of maximum stress. In turn, it is connected to a delicate galvanometer whose readings measure the temperature developed, even though it be as minute as one one-hundredth of a degree. If the test shows no development of "temperature," the "wobble" is increased and another run made. In fact this program is continued until a decided development of "temperature" is shown. The stress corresponding to the "wobble" which causes this rise of temperature is the "endurance limit" for that particular steel.

The "endurance limits" determined by this rapid "rise of temperature" test have been checked by comparison with the endurance limits obtained by the slow, tedious experiments on the rotating beam machines, and the correspondence of values is very satisfactory

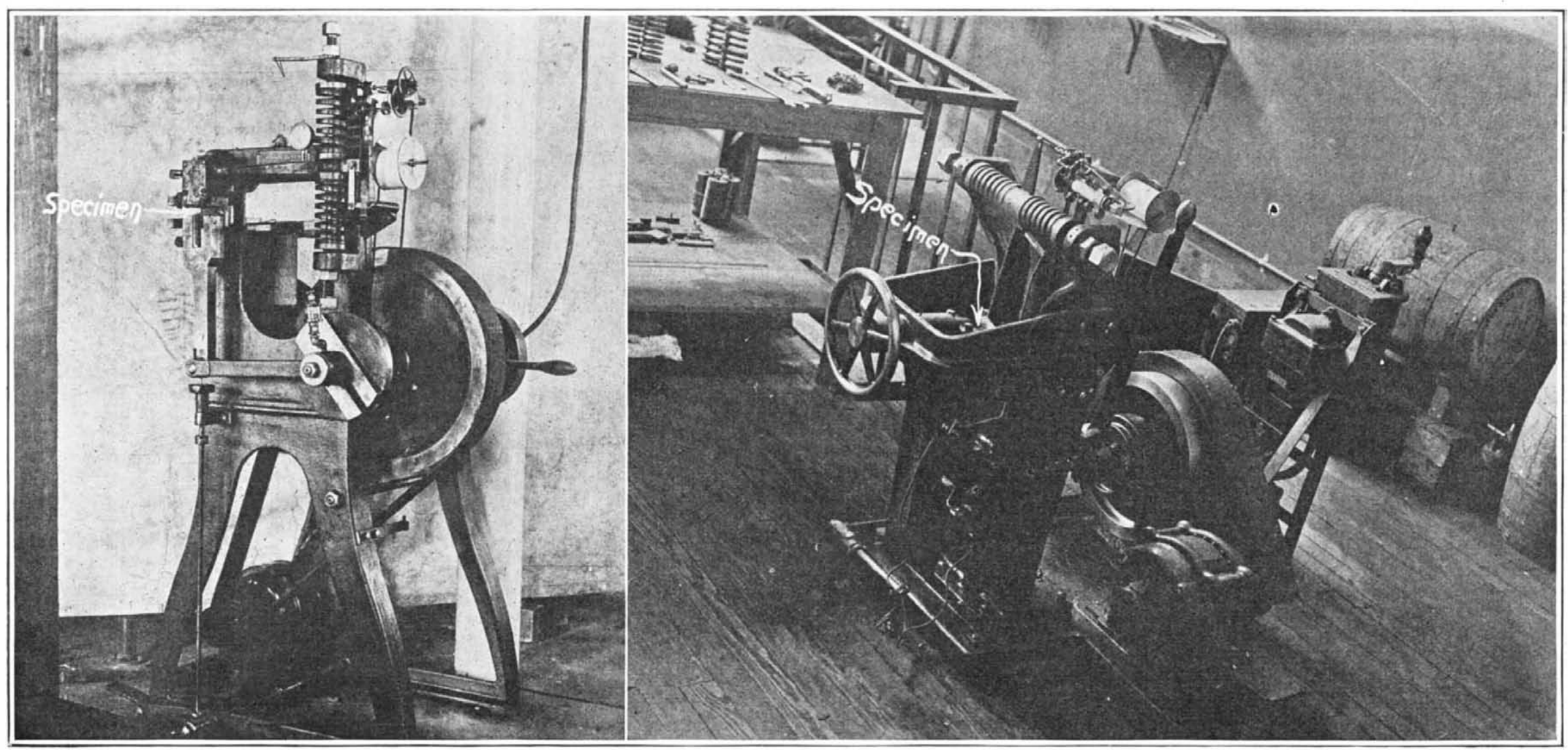

Left: Testing apparatus for repeated bending. Right: The machine that subjects the test piece to repeated twisting, which is something quite different from bending in a plane Putting steel through the acid test of long repeated stress of the same sort 